\title{
On the Value Cultivation of Chinese University English Majors*
}

LI Rui

China Youth University of Political Studies, Beijing, China

\begin{abstract}
Foreign language education should integrate cultural teaching into the training of linguistic skills. Values, as the core of culture and moral education, should be paid enough attention to. During the study process of Chinese university English majors, they inevitably encounter enormous information of Western cultures and values, and their own values may come into conflict with the ones they meet. So the English teachers have the responsibility to help the students construct correct values. Such principles as cultivating critical thinking, offering the course of Chinese culture and using group discussions and activities should be followed during instruction to facilitate the value cultivation among English majors.
\end{abstract}

Keywords: values, culture, foreign language education, Chinese university, English majors

\section{Introduction}

Every language corresponds to specific culture and values. Therefore, foreign language education should address not only basic language skills, but also cultural judgment and sensitivity, guiding the students to form correct values. In such an era of cultural globalization, the cultural interaction has become more and more frequent among different countries and regions. Values, as the core of culture, inevitably conflict and blend with each other at the same time. In such cases, foreign language education should help students keep their minds clear and construct proper values when coping with foreign cultural impacts.

\section{Foreign Language Education and Values}

\section{Language as the Vehicle of Culture}

Language is the tool of human thinking and interaction. People use language to express thoughts and emotion, and pass on information, which all correlates with certain culture. According to Goodenough's (1996, p. 116) definition, culture is the kind of knowledge acquired through social interaction. Language, as a unique linguistic skill of human beings, is an acquired knowledge system triggered by social linguistic environment. Hence, language is part of culture, and they are closely related to each other.

\section{Values as the Core of Culture}

Values are the aggregation of standpoints, perspectives, and attitudes that people adopt when they are dealing with value relations. Values permeate socioeconomic, moral, cultural, and personal life (CHEN, 2004, p. 6). Values are a cultural concept. As the core of culture, values represent each culture's ideology. Accordingly,

\footnotetext{
* This 2013 project is subsidized by China Youth University of Political Studies (No. 182060314).

LI Rui, lecturer, master, Foreign Language Department, China Youth University of Political Studies.
} 
in a deeper sense, cultural differences are value differences; cultural conflicts are value conflicts. Gradually formed through socialization, the relatively stable construction of value choices has its distinctive nationality and tendency. It serves as guide to action as to what to believe in, what to ask for, what to stick to, and what to go after. Once established, the values will not change easily, so different cultures can be distinguished according to different values.

\section{Comparison Between Chinese and Western Values}

Professor ZHANG (1989, p. 10) pointed out that both Chinese and Western values center around the relationship of collectivism and individualism, of morals and profits, of sense and desire, and of virtue and power, but each has its own emphases.

Firstly, Chinese traditional values stress the benefits of nation and group, while Western values emphasize individualism. Secondly, Chinese traditional values stress morality, while Western values highlight materialism. Thirdly, Chinese stress inner values and character, while Westerners cherish outer values and profits. Lastly, Chinese traditional values stress moderation, kindness, empathy, and harmony, while Western values pay more attention to competition.

There are both advantages and disadvantages in the two cultures. There is no such thing as one culture being better than the other when Western culture is compared with Chinese culture. Generally speaking, the merit of Chinese traditional values is the emphasis on the interests of mass people, social responsibility, harmony, and moral values; the demerit is its lack of humanity, human rights, competition, openness, and innovation. The merit of Western values is the emphasis on individual freedom, competition, exploration, and innovation; the demerit is the negligence of collectivism and ethical values. These two kinds of values can neither be totally accepted nor be wholly discarded based on the judgment of idealism and metaphysics. Instead, it is appropriate to apply materialist dialectics to analyze them, absorbing their essence and abandoning their dross.

\section{The Close Relationship Between Foreign Language Education and Value Cultivation}

As professor QIAN Guan-lian (2005, p. 21) noted, languages of various peoples are not only symbol systems or communication tools, but also meaning and value systems that people use to understand and interpret the world. Therefore, language has the characteristics of nationality and humanity. From this perspective, foreign language learning is more than learning the language itself. It also involves the learning of the target culture. So language education cannot go without culture and value information. Usually, by learning one language, people get to know its culture and value system, which facilitates the target language acquisition and application at the same time. Consequently, it is crucial to associate language with culture in language teaching, infusing cultural knowledge and revealing relevant values.

Students should on the one hand understand both the relationship between behaviors and values of the target culture and the relationship between cultural representation and cultural concepts; on the other hand, they should deepen the understanding of their own national culture when they come to know more of the foreign cultures. In this way, students can gain an insight into the target language and the cultural essence and can truly understand the denotation and connotation of culture by comparing target language culture and their native culture.

American foreign language educators and researchers agree that cultural learning is more than knowing basic cultural facts, which are summarized by Banks into four words started with "F": Food, Fashion, Festivals, 
and Folklore (as cited in CHEN, 2004, p. 28). Real cultural learning should go deep into the core of culture, that is the comprehension of values. Since the values that formed in various cultures may differ sharply, language learners should cultivate cultural awareness and treat different cultures and values equally and normally, understanding and tolerating the discrepancy between target culture and native culture when keeping the superiority of their own culture. Garcia brought forward several principles on how to correctly treat target culture, especially the different values embedded in it, which include examining cultural differences critically; learning self-control; respecting diverse cultures with self-respect; reading extensively in order to get a comprehensive picture of the target culture and refraining from producing stereotypes or overgeneralization (as cited in GAO, 1996, p. 121). American foreign language teachers stress the method of comparison in the instruction of foreign cultures, asking the students to observe and reflect on foreign cultures critically, clarify doubts by doing necessary researches, and explore certain foreign culture subject systematically through reading and group discussions.

In addition, the formation of values is a quiet revolution in the inner world of individuals, and it is the result of interactions between the outside world and the world within, the process of which is kind of gradual infiltration without people's awareness. Given the particular characteristic of the value formation, Chinese university English major education should pay more attention to the cultivation of values. Regarding the fact that the English majors are overwhelmed by the cultures and thoughts of Western countries such as Great Britain and the United States, English teachers have the responsibility to not only spread English language knowledge and foster the basic linguistic skills of listening, speaking, reading, writing, and translating, but also guide the students to establish the right outlook on world, life, and values, developing their noble spirituality and refined morality.

\section{The Value Cultivation in Chinese University English Major Education}

In the process of economic globalization, the development of science and technology as well as the international flow of capital provide carriers, tools, and channels for the wide and rapid spread of culture, during which Chinese culture and Western culture are continuously radiating, conflicting, and blending with each other. But at the same time, decadent thoughts and cultural dross in the West also swarm in, and effectively diffuse and penetrate into Chinese culture. Since university students are quick in reaction and apt to accept new cultures, and since English teachers spread more Western cultures than those of other disciplines during instruction, so they are more responsible and obligated to guide students to distinguish between right and wrong, to critically absorb the quintessence of Western cultures, to sift the destructive dross, and to cultivate their correct outlooks on life and values.

\section{The Changes of Values Among Contemporary University Students}

In recent years, relevant surveys of different scales show that the values of contemporary university students have changed. Most of the university students (54.04\%) prefer a new kind of values which are guided by material benefits, focusing on practicality, advocating competition, stressing the blending of individuals into the society, valuing both giving and taking, and taking into consideration the interests of the state, the collective and the individual while emphasizing the benefits of oneself (LIU, 1994, p. 40). This new type of values has already become a dominant one among university students and this change of values is closely related to the current social situations in China. 
With the deepening level of globalization as well as reform and opening up, Chinese culture is on the way to pluralism. Institutions of higher education have long been hubs of diverse cultures which merge into or clash with each other. University students are the most sensitive to those changes of cultural ideology. They have access and energy to dabble in various cultures, and they also have the passion and initiative to explore and imitate the values behind the trendy cultures. So the values of university students are under easy and direct influence of the pluralistic cultures. One of the conspicuous changes is that they prefer individualism, paying less attention to overall interests. They advocate individual freedom, pursue personal development, and emphasize self-struggle and self-fulfillment. Although they acknowledge the importance of both giving and taking, they focus more on self-interest. They regard what the society can give in return for their efforts as the condition of their value orientation, which greatly weakens the collectivist values. If students holding such values cannot receive proper guidance and instructions, they may easily slip into self-centered individualism, egoism, or even the selfish extreme-individualism.

Another striking change is that university students begin to adopt utilitarian values, focusing more on practicality. They view things from the perspective of money or self-interest, having stronger desire to seek individual profits, and lacking social responsibility. This is partly because of the influence of the ideology of pragmatism and money worship in the West. At the same time, the negative effects of material desire brought about by Chinese reform and opening up together with the optimization of market economy also jeopardize the formation of correct value among university students.

Although the development of pluralistic cultures offers university students space and freedom to choose among diverse values, they may easily encounter confusion, irresolution, and dilemmas when facing cultural conflicts due to their limited life experience and immature ability to analyze and judge problems. The quality of the university students, especially moral quality, is of vital importance to the development of a country. The ideological education should be combined with every part of the quality education and carried out throughout the whole training process. So it is essential to pay attention to the cultivation of values and morality during university English education.

\section{The Principles of Value Cultivation in University English Major Education}

University students tend to possess a rebellious characteristic when it comes to the acceptance of tradition. So during the process of value formation, they would subconsciously deviate from traditional values and pursue modern values deliberately. University English major education cannot avoid covering Western political systems, values, cultural traditions, customs, religious believes, etc., which will present themselves through the medium of language, and exert impact on the students' thoughts. Therefore, university English teachers should infuse English language instructions with moral education and bring its function of guidance into full play. The teachers should impart knowledge and educate people, cultivating students' self-awareness, and trying to bring positive influence as time goes by. The following principles should be followed during the process.

Cultivating critical thinking to treat different cultural values sensibly. Economic globalization does not mean cultural homogenization. American futurists Naisbitt and Aburdene claim in the coauthored book Megatrends 2000 that "the more intensively human beings feel they live on the same planet, the more important it becomes for every culture to preserve its own traditional characteristics" (as cited in WANG, 1996, p. 18). 
Therefore, the development of pluralistic cultures is the inevitable trend of social development, and foreign language learners will surely be impacted by values of different cultures. Students are required to have sensitivity to and insight into cultural differences, and also to learn how to deal with value conflicts. One of the effective ways is to develop critical thinking, that is a neutral viewpoint, to objectively understand and evaluate the culture and values of the target language. Culture is diversified, but the equality of its intrinsic values determines that there is no superior or inferior culture, nor noble or humble culture. Foreign language learners should not go to the extreme to exclude the culture and values of the target language due to their strong nationalism, or even totally refuse to "do as the Romans do while in Rome". Nor should they go to the opposite end to blindly worship foreign cultures and despise their own, thinking that their native culture is not as advanced as the target culture, which is based on their incomplete knowledge of the foreign culture. Teachers should guide students, through analysis and comparison of various culture and values, to develop a sense of democracy and cooperation, to learn to tolerate, to treat conflicting values openly and sensibly, and to respect different value choices. In practice, Western cultures can be taught in comparison with Chinese culture to let the students concretely realize the differences between them. For instance, when Christianity, a major Western religion is introduced, it can be juxtaposed with Chinese traditional thought—Confucianism. Through comparison, the students can clearly know the different orientations, characteristics, literary inheritance, impact, and values within the two belief frameworks. Thus, they can cultivate their cultural sensitivity and the ability to distinguish among distinct cultures, and at the same time they can learn to decrease cultural mistakes and clashes and smoothly conduct two-way cultural communication.

Offering the course of Chinese culture to consolidate the cultural identification with Chinese national spirits. Traditional culture is the spiritual link of a nation. "If people were deprived of traditions, they would have no material resources, no intelligence, no moral strength, and no insights to construct homes in the world" (p. 15), as Shils (1991) put it. Chinese traditional virtues are an invaluable asset which has been created in the thousands of years of civilization and cannot be replaced or surpassed by any other cultural essence. They have gone through vicissitudes and are still alive in the hearts of every generation, deeply influencing their minds and behaviors. These traditional virtues are not only the spiritual wealth that nourishes the Chinese nation, but also the sources of eastern civilizations. Even the individualism-centered Western countries begin to turn to the collectivist eastern countries for support to solve social and moral crises. One of the most representative shifts is the increasing popularity of the study of Confucianism, which shows the Westerners' reverence and pursuit of great eastern ethical morals. Thus, inheriting and spreading excellent traditional culture is a must to attain cultural identification and an effective way to resist the invasion foreign culture. A deeper understanding of the long history and the rich contents of national spirit can help university students to construct correct values, to promote a sense of national identity and belonging, to increase national self-respect, self-confidence, and self-pride, and to foster patriotism.

Because of their study needs, English majors have more opportunities to meet foreign cultures. But the educational purpose will not be achieved if the students accept everything from the target culture they have encountered during study without critical analysis, or blindly imitate the behaviors of the foreign people, or even negate their own culture. To learn foreign cultures does not mean to accept everything indiscriminately. Instead, the students need to learn excellent cultural essence which is valuable for the formation of values and abandon those obsolete and unhealthy beliefs. 
English majors spend most of their time on the accumulation of the linguistic knowledge and the training of communication skills and the material they get in touch with is often written in English. Such intent focus on English study alienates them from their own mother tongue and culture. So they generally have comparatively weak foundation and quality of Chinese culture, which is represented by the overall quality degradation, a lack of Chinese traditional "Li" (politeness) and trust in behavior. One effective way to reeducate English majors on Chinese national spirit is to offer the course of Chinese culture. Such course can stimulate a sense of pride and love for the nation from the students by teaching Chinese historical events, which will be helpful for nurturing their respect for the nation and fostering the formation of national responsibility. As English majors, they are going to have a systematic study about the target language and culture, which can help them deeply understand the origin of Western thoughts, customs, thinking mode as well as its restrictions on the language use. However, through the study of Chinese culture, they can obtain a new perspective to examine people and themselves, increase the stock of cultural knowledge, and perfect their knowledge structure. By reading relevant cultural books in the course of Chinese culture, the students can be reeducated systematically and comprehensively on Chinese traditional values and absorb the cultural essence to improve their humanistic quality.

Using discussions to improve the ability to recognize and comprehend conflicts and problems. Language is the carrier of information. The values of different nations will ultimately be expressed in languages, so it is inevitable to encounter a series of cultural or value problems during language learning process. The more the students learn about the target culture, as they are experiencing it in the classroom, the more cultural differences they encounter that trouble them. As Kramsch (1983) pointed out, even the most superficial reading of a textbook may generate opposition, something she refers to as "oppositional practice" (p. 25). Then here comes the necessity of group discussions which are based on the students' understanding, analysis, and hypotheses of these problems to treat the cultural conflicts openly and directly in a comparative cross-cultural manner. They can heartily express their reasonable opinions, reach realistic conclusions, and bring forward practical solutions. Truth will not be clear without being argued. It is through discussion and collision of ideas that students can learn from each other, improve the abilities to understand problems, distinguish truth from fallacy, and fulfill the purpose of self and mutual education.

Teachers can help engage students in careful thinking and critical analysis by offering relevant topics for discussions in class or designing tasks for group activities after class. Take the study of Confucianism in the author's former classes as an example. The students were asked to associate such core values of Confucianism as benevolence, morality, and harmony with the phenomena of modern society to let the students think deeply about the realistic significance of Confucianism. After heated group discussion, students fully expressed their unique understanding. Some related benevolence and morality to current social phenomena such as modern wars and computer hacking; others talked about harmony in connection with environmental protection. In this way, the students can learn to integrate theory into practice, which not only help them memorize the concrete cultural knowledge but also train their logical thinking. Moreover, the teachers can also take Christianity as the representative of Western cultures and compare it with Confucianism in order to clarify the characteristics and impact of the two different cultures. Through comparison the students can easily find the great influence both beliefs exert on respective culture. The core values of Confucianism leave their marks on Chinese culture as being "polite", "modest", and "dutiful". Chinese people attach great importance to the benefits of nation or group, 
that is collectivist values. On the contrary, Christianity which plays its religious role in the formation of Western cultures emphasizes individual efforts and encourages people to pursue independence and freedom of speech and thoughts, namely individualism. Students can discover the differences effectively and efficiently through discussion and help each other to better comprehend complicated content.

\section{Conclusion}

The German educator of 19th century Herbart said that "morality is universally considered the supreme aim of human beings and therefore it is the supreme goal of education" (as cited in HU, 2001, p. 19). It indicates the significance of moral education in overall education. Value cultivation, as the core of moral education and culture, should be paid enough attention to and get strengthened through serious training. It can be combined with the teaching of every subject. Since the education of English majors inevitably involves other cultures, the cultivation of values during language instruction appears even more crucial. English teachers should take advantage of the similarities between native culture and foreign cultures to nurture the cultural quality of the students and use the cultural conflicts to train the students' critical and logical thinking, facilitating the formation of correct values.

\section{References}

CHEN, Z. L. (2004). Research on values. Nanjing: Nanjing Normal University Press.

GAO, Y. C. (1996). Values in cross-cultural communication and English teaching. Journal of Soochow University, 2, $120-125$.

Goodenough, W. H. (1996). Culture. In Encyclopedia of cultural anthropology (pp. 115-139). New York: Henry Holt.

HU, T. F. (2001). Moral education I university English teaching. Academic Forum of Nan Du, 5, 18-21.

Kramsch, C. J. (1983). Culture and constructs: Communicating attitudes and values in the foreign language classroom. Foreign Language Annals, 16, 23-28.

LIU, X. G. (1994). Thoughts on the new kind of values among contemporary university students. Moral Education in School, 5 , 40-41.

QIAN, G. L. (2005). Language: The final home of human beings. Beijing: The Commercial Press.

Shils, E. (1991). Tradition. Shanghai: Shanghai Renmin Press.

WANG, D. H. (1996). Comparison of moral education between east and west. Comparative Education Review, 4, 17-22.

ZHANG, D. N. (1989). Research on Chinese morals. Shanghai: Shanghai Renmin Press. 